\title{
Applicability of the Colebrook-White Formula to Represent Frictional Losses in Partially Filled Unsteady Pipeflow
}

\author{
J. A. Swaffield and S. Bridge \\ Brunel University, Uxbridge, Middlesex, U.K.
}

Accepted: July 19, 1983

\begin{abstract}
The use of Manning's $n$ as a friction factor is shown to be unsuitable in the case of small bore (less than about one meter diameter) partially filled pipeflow, particularly for relatively smooth materials such as glass and cast-iron. The Colebrook. White equation with the roughness coefficient $k$ is presented in a form suitable for inclusion in a computer program to solve the partially filled unsteady pipeflow equations by means of the method of characteristics. Results are presented which show that the Colebrook-White equation provides substantially improved predictions of the wave velocity along the pipe. It provides slightly improved predictions for the maximum depth of flow along the pipe.
\end{abstract}

Key words: drains; partially filled pipeflow; pipeflow function; plumbing drainage.

\section{Introduction}

Steady-state flow tests in partially filled pipes on the Brunel test rig at various gradients have shown that the value of Manning's $n$ varies with slope (fig. 1). Similar tests at fixed gradients confirmed results reported elsewhere [2]' which are that Manning's $n$ also varies with discharge (fig. 2). This is particularly noticeable in channels of circular cross-section. Steady-state tests carried out on $100 \mathrm{~mm}$ diameter castiron pipe produced values of Manning's $n$ from 0.008 to 0.01 , values not significantly different from those

About the Authors: J. A. Swaffield heads the Drainage Research Group in the Department of Building Technology at Brunel University where S. Bridge is completing her doctoral program. Dr. Swaffield directs the NBS grant program at Brunel and from time to time since 1980 has conducted research as a guest worker in the Building Equipment Division of the NBS Center for Building Technology.

\footnotetext{
'Figures in brackets indicate literature references at the end of this paper.
}

found for $100 \mathrm{~mm}$ diameter glass pipe. It was felt that these values were too low and were not representative of the roughness of the cast-iron. Manning's coefficient was originally derived for large open channels of rectangular cross-section with fully rough flow. This led to doubts about the validity of using Manning's

\begin{tabular}{|ll|}
\hline & \multicolumn{1}{c|}{ Notation } \\
$A$ & cross-sectional area of flow $\left(\mathrm{m}^{2}\right)$ \\
$C$ & Chézy coefficient $\left(\mathrm{m}^{1 / 2} / \mathrm{s}\right)$ \\
$D$ & pipe diameter $(\mathrm{m})$ \\
$f$ & Darcy resistance coefficient \\
$g$ & acceleration due to gravity $\left(\mathrm{m} / \mathrm{s}^{2}\right)$ \\
$k$ & roughness coefficient $(\mathrm{m})$ \\
$n$ & Manning's $n\left(\mathrm{~m}^{-1 / 3} \mathrm{~s}\right)$ \\
$Q$ & discharge $\left(\mathrm{m}^{3} / \mathrm{s}\right)$ \\
$R$ & hydraulic radius $(\mathrm{m})$ \\
$\operatorname{Re}$ & Reynold's number $($ characteristic \\
$S$ & $\quad$ length equal to the hydraulic radius) \\
$V$ & channel slope \\
$\nu$ & velocity of flow (m/s) \\
\hline
\end{tabular}




\section{The Colebrook-White Equation}

The Colebrook.White equation for pipeflow may be written:

$$
\frac{1}{\sqrt{\tilde{J}}}=-2 \log _{10}\left[\frac{k}{14.83 R}+\frac{2.52}{\operatorname{Re}^{\vee} f}\right]
$$

where

$$
\begin{aligned}
f= & \text { Darcy resistance coefficient } \\
k= & \text { roughness coefficient }(\mathrm{m}) \\
R= & \text { hydraulic radius (m) } \\
\operatorname{Re}= & \text { Reynold's number (characteristic length } \\
& \text { equal to the hydraulic radius) }
\end{aligned}
$$

The Colebrook-White equation for full bore pipeflow may be developed from the general equation by taking the hydraulic radius $R$ to be equal to $D / 4$ where $D$ is the pipe diameter in meters. The Chézy equation may be written,

$$
V=C \sqrt{R S}
$$

where

$$
\begin{aligned}
& V=\text { velocity of flow }(\mathrm{m} / \mathrm{s}) \\
& S=\text { channel slope } \\
& C=\text { Chézy coefficient }=\sqrt{\frac{8 \mathrm{~g}}{f}} \\
& g=\text { acceleration due to gravity }\left(\mathrm{m} / \mathrm{s}^{2}\right)
\end{aligned}
$$

This equation was developed for large open channels and later used to produce Manning's equation, however the effect of cross-sectional channel shape on the Chézy coefficient has been shown to be limited [3] and it may be used for channels which are moderately smooth [1]. Manning's equation is based on the empirical relationship $C=R^{1 / 6} / n$. Reynold's number is expressed thus,

$$
\operatorname{Re}=\frac{4 \mathrm{QR}}{A \nu}
$$

where

$$
\begin{aligned}
& Q=\text { discharge }\left(\mathrm{m}^{3} / \mathrm{s}\right) \\
& A=\text { cross-sectional area of flow }\left(\mathrm{m}^{2}\right) \\
& \nu=\text { kinematic viscosity of water }\left(\mathrm{m}^{2} / \mathrm{s}\right)
\end{aligned}
$$

It is important to use the correct characteristic length for the Reynold's number; here it is the hydraulic radius of flow. From these equations the following expression is derived:

$$
Q=\sqrt{32 g R S} A \log _{10}\left[\frac{k}{14.83 R}+\frac{2.52 v}{R \sqrt{128 g R S}}\right]
$$

This equation may be used to calculate both normal depth and also the initial steady-state loss.

\section{The Roughness Coefficient}

The coefficient $k$ is a length parameter characteristic of the surface roughness and is defined as the sand-grain diameter for a sand-coated surface having the same value of $f$, the Darcy resistance coefficient, as the pipe under consideration. Commenting on Nikuradse's equation for fully rough flow, Henderson [1] says that although it is not easy to determine accurate values of $k$, this is not a problem since the logarithmic relationship in the equation means that large errors in the value of $k$ produce only small errors in the value of $C$.

This observation also applies to eq (1) so that slightly inaccurate values of $k$ do not give rise to serious errors in the value of $Q$. The Transport and Road Research Laboratory Roadnote No. 35 [4] provides a comprehensive list of $k$ values for a wide variety of materials and channel types including the pipe materials currently being used on the Brunel test rig. Glass is generally agreed to be smooth and to have an effective roughness value of zero, cast-iron varies between about 0.1 and $0.3 \mathrm{~mm}$ and a value of $0.2 \mathrm{~mm}$ was used for the laboratory test pipe. Table 1 gives values for some of the more commonly used pipe materials.

\section{Results}

\subsection{Wave Velocity}

Figures 4 and 5 show the time at which the maximum depth occurs along the pipe during the passage of a wave for two different gradients. The graphs compare results from an earlier report ([5], figs.

Table 1. $k$ values for various pipe materials;

\begin{tabular}{lc}
\hline \hline Pipe material & $k(\mathrm{~mm})$ \\
\hline Glass & 0.0 \\
PVC & 0.002 \\
Coated cast-iron & $0.1-0.3$ \\
Uncoated cast-iron & $0.15-0.6$ \\
Glazed clay & $0.15-0.6$ \\
\hline
\end{tabular}




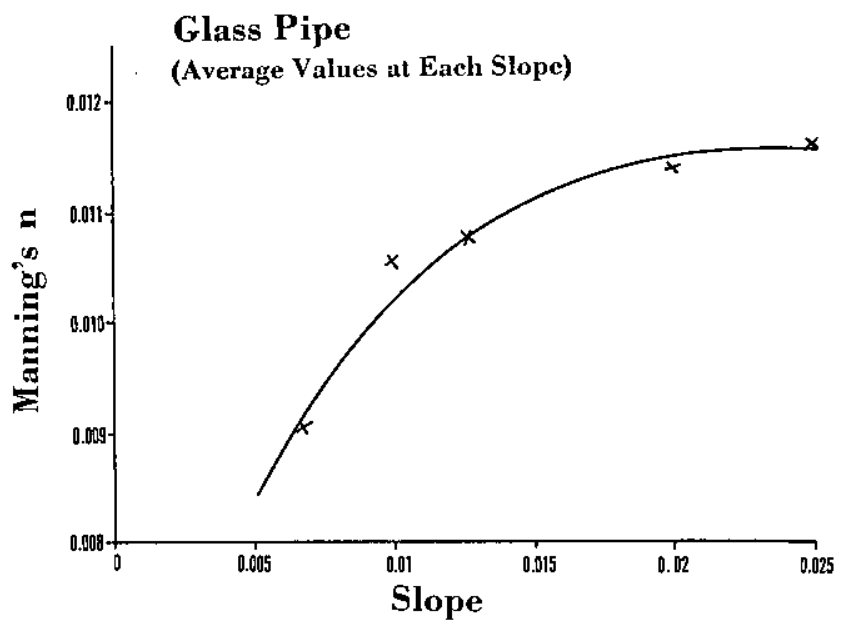

Figure 1-Variation of Manning's $n$ with slope.

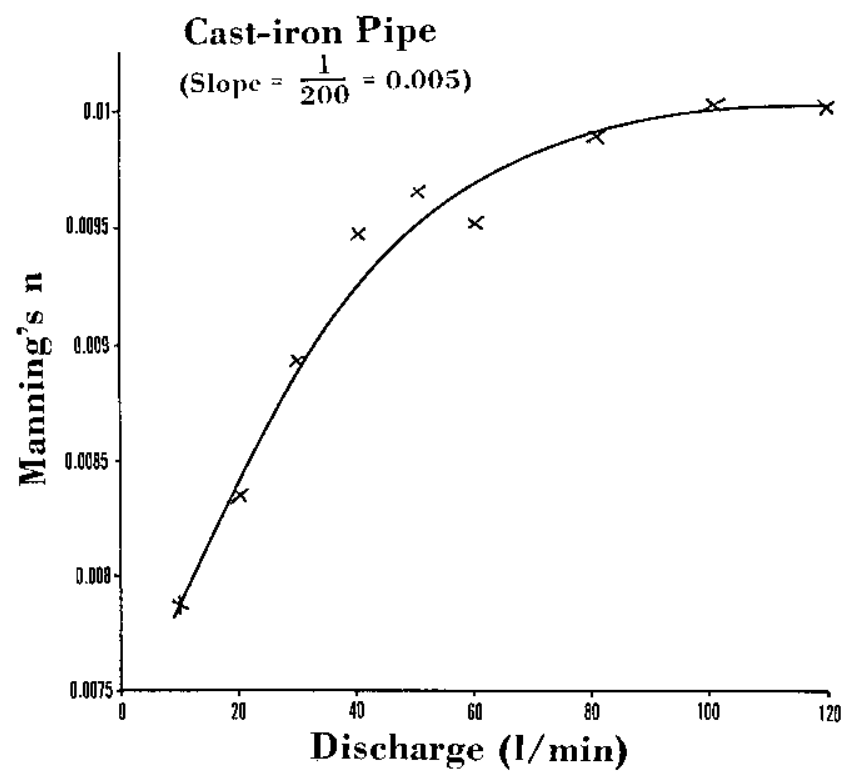

Figure 2-Variation of Manning's $n$ with discharge.

coefficient for small bore partially filled pipeflow, and these doubts were reinforced by the above findings.

The roughness of a pipe is dependent on the flow conditions. If the roughness projections are buried within the laminar sublayer, the pipe is hydraulically smooth; as the laminar sublayer shrinks, the projections assume a greater significance until they break through the sublayer and the flow becomes fully rough. Moderately smooth surfaces such as glass, PVC, cast-iron, etc. produce flows which are in the transitional stage between hydraulically smooth and fully rough flow. Their behavior is described by the Colebrook-White equation [1].

The question of friction factors in open channels was studied by a committee of the American Society of Civil Engineers [3] which found the ColebrookWhite equation to be more reliable than the Manning equation with a constant value of $n$. For any given channel it was found that the roughness value $k$ (used in the Colebrook-White equation) was more likely to be constant than Manning's $n$. The Colebrook-White equation, unlike Manning's expression, is based on empirical studies of pipeflow and is suitable for partially filled pipeflow provided the surface is moderately smooth hydraulically and the pipe diameter fairly small [1]. Figure 3 shows the change in Manning's $n$ with discharge at two gradients with a fixed value of the roughness coefficient $k$ (the depth for each discharge was found from the ColebrookWhite equation and Manning's $n$ calculated using the known depth and discharge) and further demonstrates the variation of the Manning coefficient compared to the roughness coefficient $k$.

The flow in open channels has long been characterized via experimental data and empirical relationships. Foremost among these relationships is the one associated with the work of Manning giving rise to the roughness coefficient known as Manning's $n$ ([1], pp. 96,101). This technology has since been transferred to the flow of liquids in partially filled conduits.

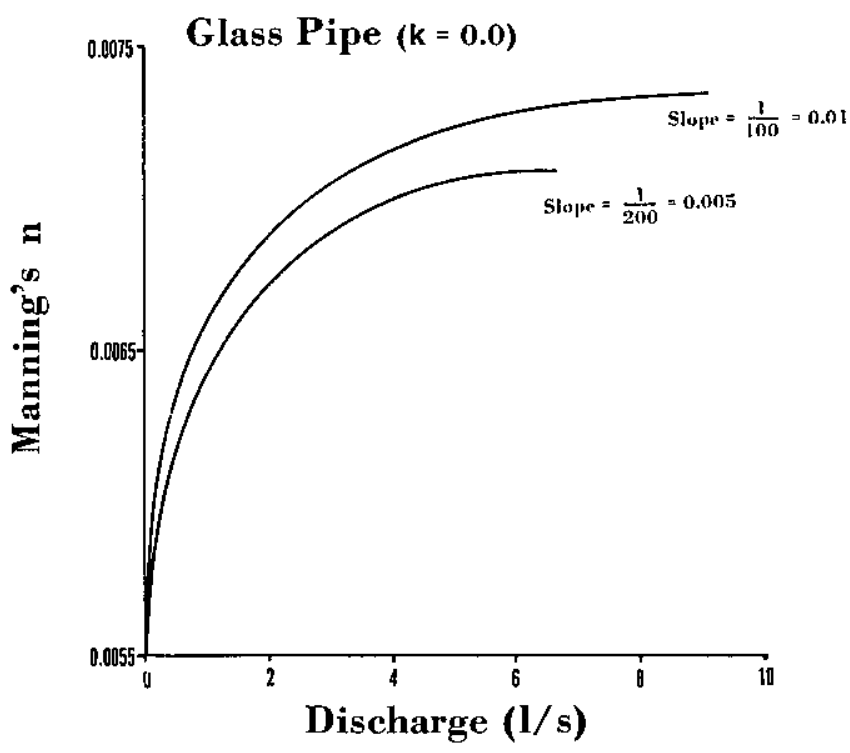

Figure 3-Variation of Manning's $n$ with discharge for a fixed roughness value. 


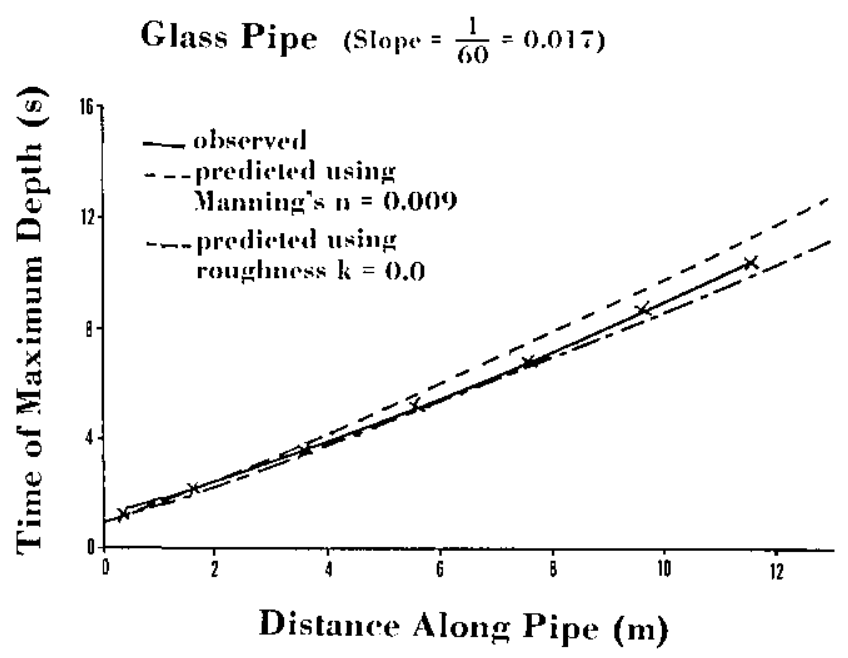

Figure 4-Time of maximum depth versus distance (gradient $=1 / 60=$ $0.017)$.

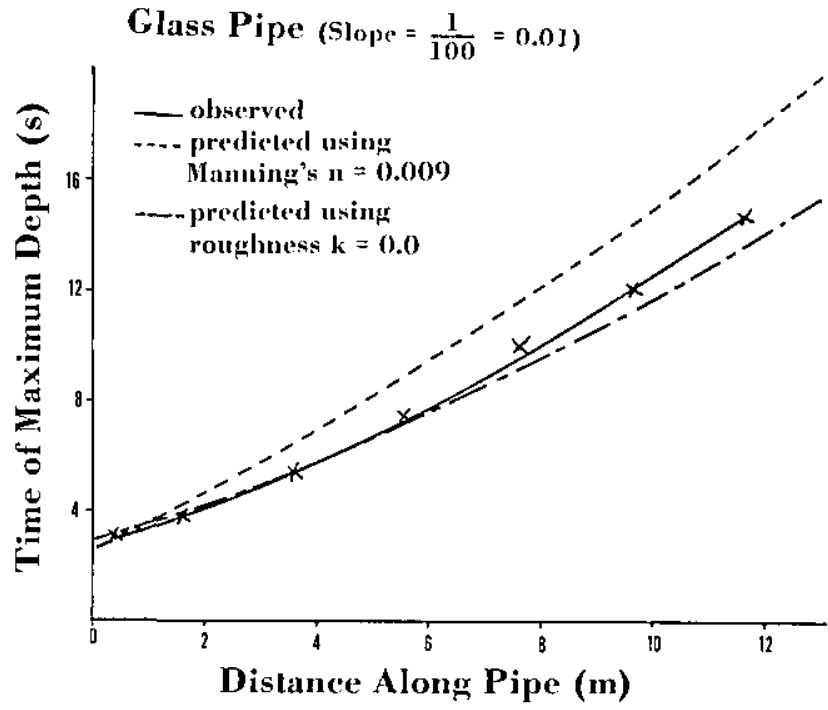

Figure 5-Time of maximum depth versus distance (gradient= $1 / 100=0.01)$.

6 and 8) using Manning's $n$ with results obtained from running the same data through the program with the Colebrook-White equation for calculating the normal depth and steady-state loss. In both cases the use of the Colebrook-White equation improves the prediction of the velocity of the wave peak along the pipe due to the constancy of the value of the roughness coefficient $k$ with changing depth of flow. Any value of Manning's $n$ used is only valid for one discharge and will therefore over- or under-estimate the loss as the wave travels along the pipe. The Colebrook-White
Glass Pipe (Slope $=\frac{1}{50}=0.02$.

Critical Depth at Entry)

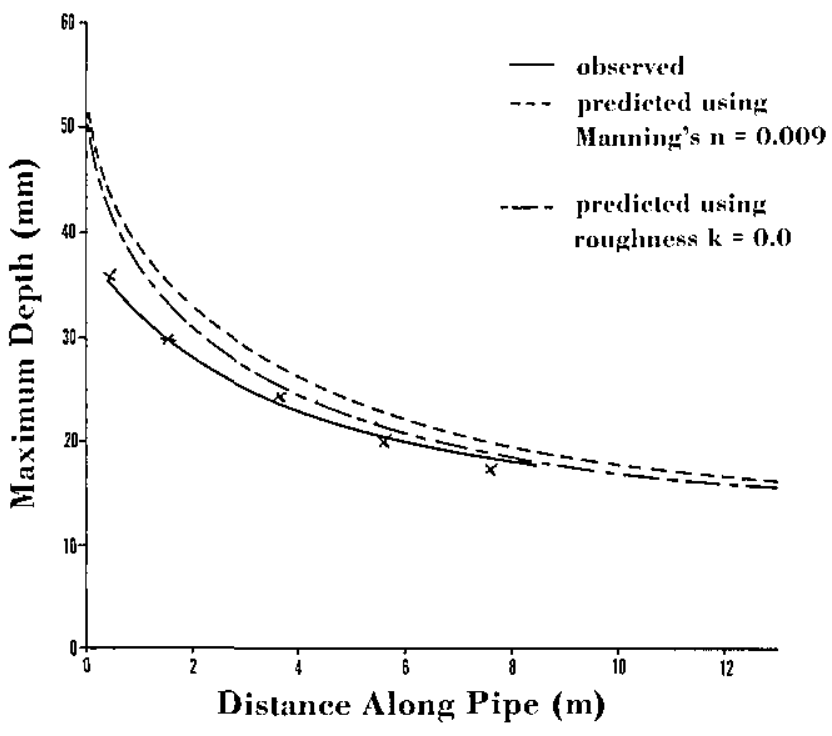

Figure 6-Maximum depth versus distance for glass pipe (gradient = $1 / 50=0.02$ ).

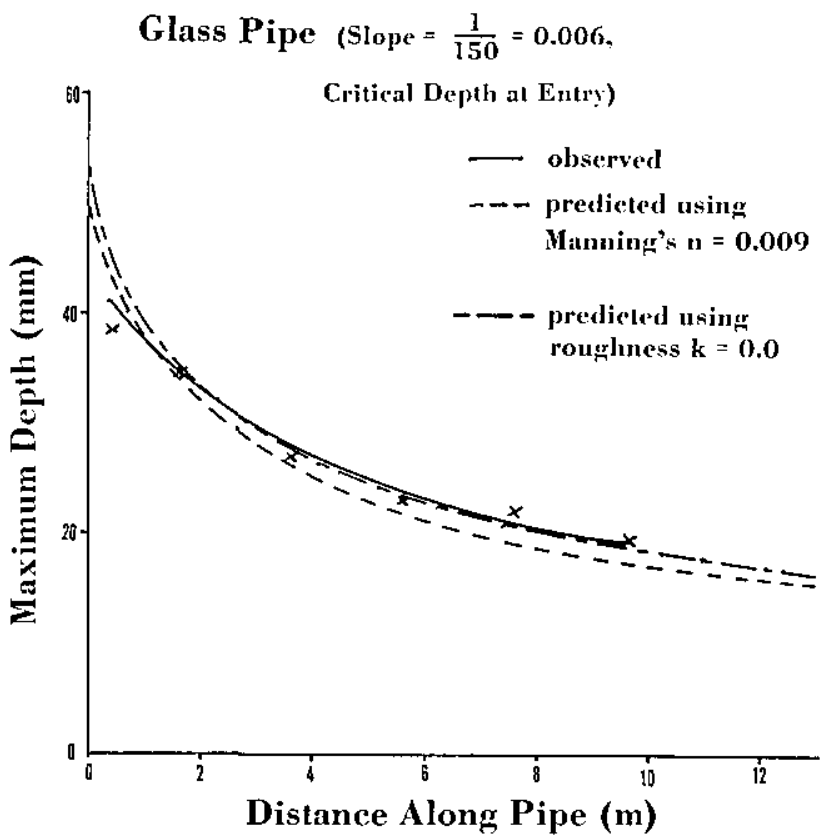

Figure 7-Maximum depth versus distance for glass pipe (gradient= $1 / 150=0.006)$.

equation allows the loss to be calculated for each node at each time-step, thus significantly reducing the error in estimating the loss. 


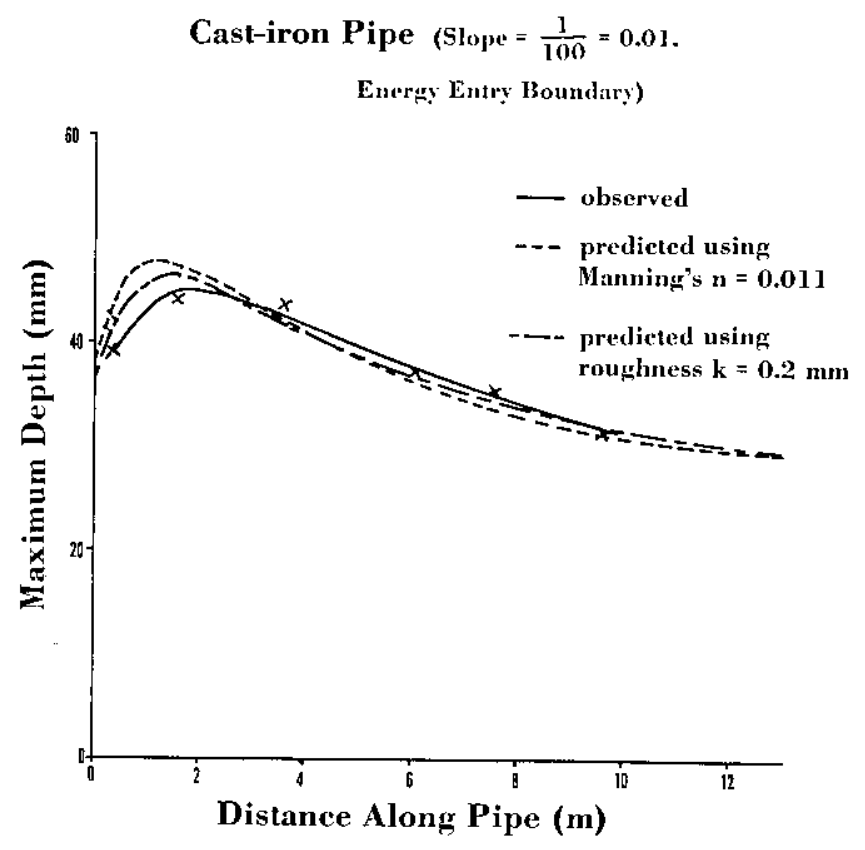

Fure 8-Maximum depth versus distance for cast-iron pipe $\because$ (gradient $=1 / 100=0.01)$.

\subsection{Maximum Depth}

Figures 6 and 7 show the maximum depth of flow as the wave attenuates along the pipe at two different gradients with critical depth at the entry boundary. In both cases the Colebrook-White equation provides a better prediction of the attenuation of the wave, occasionally the improvement is marginal but generally justifies the use of the roughness coefficient $k$ instead of Manning's $n$. Figure 8 shows the result of a wave from a drop-valve cistern attenuating along a cast-iron pipe, a $k$ value of 0.2 is used and produces a significantly better result than does Manning's equation. The Colebrook-White equation performs far more satisfactorily for the cast-iron pipe than does Manning's equation, which is undoubtedly due to the stability of $k$ over a range of discharge values.

\section{Conclusion}

The Colebrook-White equation and roughness coefficient $k$ generally predict wave attenuation in both glass and cast-iron pipes with greater accuracy than does Manning's equation. The improvement is particularly noticeable in the prediction of the velocity of the wave peak along the pipe. The variation of Manning's coefficient with both depth and pipe gradient, particularly for circular small-bore pipes (i.e. less than about one meter diameter) highlights the utility of the empirical Colebrook-White equation.

\section{References}

[1] Henderson, F. M. Open Channel Flow. New York, NY: MacMillan; 1966, 90-101.

[2] Camp, T. R. Design of sewers to facilitate flow. Sew. Works Journal 18, 1; 1946.

[3] Report, A.S.C.E. task force on friction factors in open channels. Proc. A.S.C.E. 89, HY2: 97-143; 1963.

[4] Transport \& Road Research Laboratory, A guide for engineers to the design of storm sewer systems. T.R.R.L. Roadnote No. 35, H.M.S.O.; 1975.

[5] Swaffield, J. A.; Bridge, S. Experimental vertification of predicted wave attenuation in partially filled drainage pipeflow. DreG/NBS/1 interim progress report to NBS Washington under grant DA 2004; 1981 June. 